\title{
The architecture of the nervous system of Echiniscus testudo (Echiniscoidea, Heterotardigrada)
}

\author{
Corinna SCHULZE, ${ }^{*}$ Andreas SCHMIDT-RHAESA \\ Zoological Museum Hamburg, Martin-Luther-King Platz 3, 20146 Hamburg \\ *Corresponding author: corinna_schulze@gmx.de
}

\begin{abstract}
Despite the fact that there are several descriptions of the nervous system of Tardigrada there is still dispute about how to interpret the organisation of these structures. Is the structure of the brain homologous to segmental equivalents of the arthropod brain or not? The latest studies concerning these questions concentrate on specimens from the taxon Eutardigrada, but a representative of Heterotardigrada has been missing. Therefore, in this immunohistochemical study the organisation of the nervous system of Echiniscus testudo is investigated and can be described as follows. In the brain of E. testudo several distinct regions can be recognised. These are the anterior, dorsal, dorsoventral, inner and posterior clusters. Furthermore a ventral cluster can be detected that is connected to the dorsoventral clusters. The brain is followed by four ventral ganglia that are positioned slightly anterior to their corresponding pair of legs. The brain and the first ventral ganglion are connected via connectives showing tyrosinated $\alpha$-tubulin and RFamide immunoreactivity. A connection between the first ventral ganglion and the ventral cluster could not be detected, at least not with our antibody set. In longitudinal direction the ventral ganglia are chained by connectives, and transversal interconnections via commissures are present. In addition to the commissures connecting the hemiganglia, three commissures could be detected lying anterior to the second, the third and the fourth ventral ganglion. In some specimens between the second and the third ganglion, bilaterally arranged neurites could be detected that run in a loop to the dorsal part of the specimens. The hereindescribed organisation is compared with previously published data on the nervous system of Tardigrada, and we conclude that the lobate organisation of the brain of E. testudo comprises an arrangement due to functional needs rather than to reflect an organisation into arthropod-like proto-, deuto- and trito-cerebrum.
\end{abstract}

Key words: nervous system, Heterotardigrada, immunohistochemistry.

\section{INTRODUCTION}

The taxon Tardigrada consists of approximately 1,200 described species from marine, freshwater and terrestrial habitats (Guidetti and Bertolani, 2005; Degma and Guidetti, 2007; Degma et al., 2012). Tardigrada are often described as enigmatic and one of the minor neglected phyla, which is partly due to their microscopic size, as well as to their lack of economic importance to humans (Nelson, 1991). Probably, in part this is the reason why the debate about the phylogenetic position of Tardigrada is still going on. Neither the phylogeny within Tardigrada nor the relationships to other taxa are totally resolved. The taxon is classified into the two probably monophyletic groups Heterotardigrada and Eutardigrada (Nichols et al., 2006; Jørgensen et al., 2010). A third taxon, the Mesotardigrada, has been described by Rahm in 1937 (Rahm, 1937a, 1937b), but since then has never been found again (Ramazzotti and Maucci, 1983; Kinchin, 1994). The Heterotardigrada and the Eutardigrada are divided into two taxa each, the Arthrotardigrada and the Echiniscoidea, and the Apochela and the Parachela, respectively. This traditional classification is based on morphological data (Marcus, 1929; Schuster et al., 1980; Ramazzotti and Maucci, 1983 ), but the validity of these taxa is still under discussion (Jørgensen and Kristensen, 2004; Sands et al., 2008;
Guidetti et al., 2009; Jørgensen et al., 2010, 2011; Guil and Giribet, 2012). The Tardigrada possess morphological features that show similarities to both Panarthropoda (including Arthropoda and Onychophora) and Nematoda (Crowe et al., 1970; Dewel and Clark, 1973a, 1973b, 1973c; Schmidt-Rhaesa et al., 1998; Giribet, 2003). Likewise, molecular data concerning the grouping of Tardigrada are inconsistent. They are either grouped within Panarthropoda or are related to Nematoda depending on the analyses used (Dunn et al., 2008; Rota-Stabelli et al., 2011). It seems that the grouping of Tardigrada together with Nematoda is due to model depending errors, and the position of Tardigrada within Panarthropoda is more likely (Campbell et al., 2011; Rota-Stabelli et al., 2011; Giribet and Edgecombe, 2012). To give an input to these still ongoing debates it might help to have a further look at the organisation of the nervous system. So far there have been several studies on the nervous system of Tardigrada, starting with light microscopical investigations in the middle of the nineteenth and beginning of the twentieth century (Doyère, 1840; Greeff, 1865; Plate, 1889; Basse, 1905; Marcus, 1929), followed by electron microscopical examinations (Greven and Kuhlmann, 1972; Walz, 1978, 1979; Kristensen, 1981; Dewel and Dewel, 1996; Wiederhöft and Greven, 1996, 1999; Dewel 
et al., 1999) and in recent years by immunohistochemical studies (Zantke et al., 2008; Persson et al., 2012). Nevertheless, there are still different hypotheses on how to interpret the structure of the nervous system of Tardigrada. Within Tardigrada, information is more prevalent on Eutardigrada. This and the fact that there is still an ongoing debate about the organisation of the nervous system of Tardigrada led to the immunohistochemical study of Echiniscus testudo (Doyère, 1840), a member of Heterotardigrada.

\section{METHODS}

Specimens of E. testudo were extracted from moss collected in Hamburg, Germany (N53'27'21.373", E10 8'30.192"), between October 2009 and October 2010. Moss was kept in a freezer at $-20^{\circ} \mathrm{C}$ and for extraction was soaked in tap water. The sample was sieved through a large-size mesh screen to keep large moss fragments from the remnant that was collected in a measuring cylinder. After $20 \mathrm{~min}$ the supernatant was discarded and the remaining material was sorted for tardigrades.

Prior to fixation all specimens were relaxed with carbonated water. Some specimens were treated with $30 \mathrm{~s}$ ultrasonication and after fixation were additionally treated with liquid nitrogen. Specimens were fixed with $4 \%$ paraformaldehyd in $0.1 \mathrm{M}$ phosphate-buffered saline [(PBS) $\mathrm{pH} 7.3$ ] overnight on ice. Fixation was stopped by several washing steps with $0.1 \mathrm{M}$ PBS. All specimens were either cut with a sapphire scalpel or punctured with a needle $(\varnothing 0.22 \mathrm{~mm})$. Afterwards, samples were put into a pre-incubation buffer [(PIB) $0.5 \%$ bovine serum albumin, 6\% normal goat serum, $2 \%$ Triton X-100, 1\% dimethylsulfoxide (DMSO) and $0.05 \%$ sodium azide $\left(\mathrm{NaN}_{3}\right)$ in $\left.0.1 \mathrm{M} \mathrm{PBS}\right]$ overnight at $37^{\circ} \mathrm{C}$. Primary antibodies were diluted in antibody buffer [(ABB) $0.1 \mathrm{M}$ PBS containing $2 \%$ Triton $\mathrm{X}-100,1 \%$ DMSO and $0.05 \%$ $\mathrm{NaN}_{3}$ ] or PIB. The following primary antibodies were used (dilution, host and supplier are provided in brackets): anti-FMRFamide [1:800, rabbit, ImmunoStar (Hudson, WI, USA)], and anti-tyrosinated $\alpha$-tubulin [1:400, mouse, Sigma Aldrich (St. Louis, MO, USA)]. The treatment with primary antibodies lasted three to four nights at $37^{\circ} \mathrm{C}$ and was followed by washing with $0.1 \mathrm{M}$ PBS for several times. Secondary antibodies were diluted in ABB or PIB overnight at $37^{\circ} \mathrm{C}$. The following secondary antibodies were used, dilution, reacting against, host and supplier in brackets: $\mathrm{Cy}^{\mathrm{TM}} 5$-conjugated [1:100, anti-rabbit, goat, Jackson (West Grove, PA, USA)], DyLight ${ }^{\mathrm{TM}}$ 488-conjugated (1:100, anti-mouse, goat, Jackson). Additionally, staining of the nuclei was conducted with 4', 6-diamidino2-phenylindol [(DAPI), Sigma]. In addition, $1 \mu \mathrm{L}$ DAPI $\left(1 \mathrm{mg} \mathrm{mL}^{-1}\right.$ distilled water) per $100 \mu \mathrm{L}$ solution was either added to the secondary antibody solution overnight at $37^{\circ} \mathrm{C}$, to the first washing step with $0.1 \mathrm{M} \mathrm{PBS}$, or to aqua bidest. for the latter for $1 \mathrm{~h}$ at room temperature. Afterwards, samples were rinsed several times with $0.1 \mathrm{M}$ PBS and embedded in Citifluor on microscopical slides. For the samples that were treated with DAPI in aqua bidest. two washing steps with aqua bidest. preceded the washing with $0.1 \mathrm{M}$ PBS. Stainings were prepared as triple-labelling with anti-FMRFamide, anti-tyrosinated $\alpha$-tubulin and DAPI.

Due to difficulties in the staining of the nervous system of Tardigrada that often can be reflected in only partially stained structures several replicates are needed. Triple-labelling was applied to all samples, but in some cases only one or two stainings were successful. In the following the numbers of (partial) stained individuals that could be used for each antibody are listed: anti-FMRFamide: 32; anti-tyrosinated $\alpha$-tubulin: 31 . For the DAPI stainings 31 individuals could be used.

For the negative controls primary antibodies were omitted during the staining procedure and except of autofluorescence of cuticular structures no other fluorescence could be detected.

Samples were investigated with a confocal laser scanning microscope Leica TCS-SPE and recorded with Leica software (LAS AF; Leica, Wetzlar, Germany). ImageJ software (ImageJ 1.46d, National Institutes of Health, Bethesda, MD, USA) was used for imaging and post-processing the data. Volume render were created using voltex function (colourmap: volrenGlow.am) of Amira software (Amira 5.4.1, Visage Imaging Inc., San Diego, CA, USA).

For the structures of the nervous system we try to follow the nomenclature of the neuroanatomical glossary of Richter et al. (2010).

\section{RESULTS}

Although it is sometimes hard to recognise areas which show a well defined structure in the meshwork of immunoreactive neurites and somata or a clear arrangement of nuclei we herein describe several clusters. Such clusters are structures that can be distinguished from surrounding structures either by recognition of immunoreactivity (IR) of neurites and/or somata against the used antibodies (anti-FMRFamide and/or tyrosinated $\alpha$-tubulin) and/or by nuclei arrangement.

\section{General structure of the brain and associated clusters}

The brain is formed of several distinct regions. These regions are characterised by specific clusters of neuronal somata and specific sets of neurites. Dorsal of the pharynx the largest definable cluster, the dorsal cluster (dcl), is of a compact structure and stretches over the midline of the body axis (Fig. 1a). It encloses a number of transversal and longitudinal neurites (Figs. 2 and 5). Additional to the dorsal cluster there are bilaterally arranged clusters of neuronal 
somata and associated neurites. One pair of clusters is located anterior of the dorsal cluster and therefore the two clusters are called the anterior clusters (acl) (Figs. 1a, 2c, and $2 \mathrm{~d}$ ). Another pair of clusters is positioned in line with the posterior layer of neuronal somata of the dorsal cluster and these two clusters are called the posterior clusters (pcl) (Figs. 1a, 2a, and 2b). A third pair of clusters lies posterior of the dorsal cluster. These clusters are called inner clusters (icl) (Figs. 1a and 2a). Ventral of the pharynx a cluster $(\mathrm{vcl})$ of neuronal somata can be recognised (Fig. $1 \mathrm{~b}$ and 1c). Like the cluster of neuronal somata of the dorsal cluster it encloses transversal neurites. Furthermore, a pair of dorsoventral clusters ( $\mathrm{dvcl}$ ) including neurites can be recognised (Fig. 3a and 3b). These clusters are also distinguishable by the arrangement of nuclei (Fig. 1b). They are connected to the dorsal part of the brain and the ventral cluster on a broad base (Figs. 1b and 3b).

\section{Dorsal and ventral commissures}

The brain exhibits a great number of transversal and longitudinal neurites. In this confusing meshwork it is very hard to recognise single neurites. But there are at least six
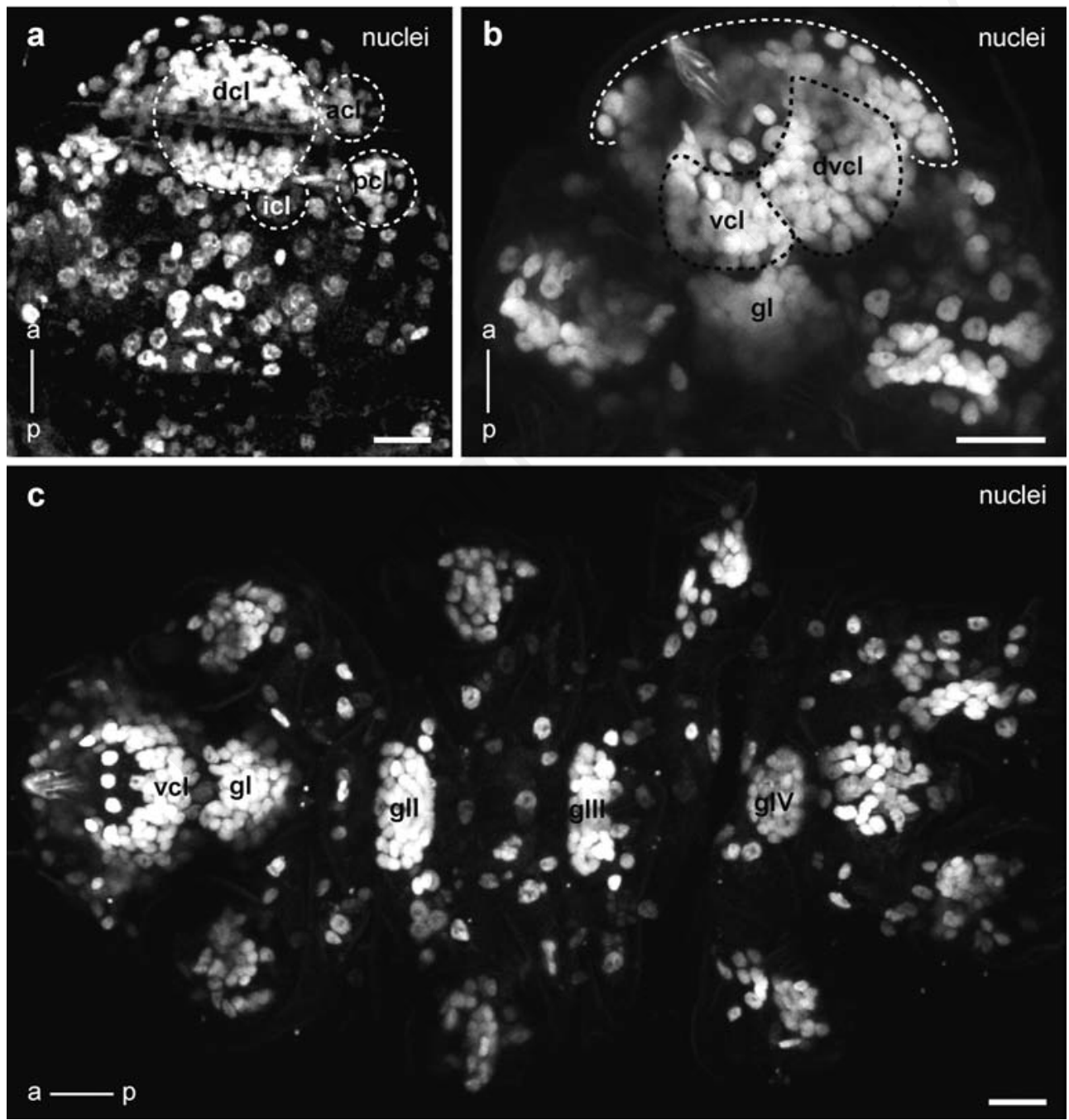

Fig. 1. Echiniscus testudo, staining of the nuclei, maximum projection, anterior and posterior direction are indicated with the help of an axis. a) Dorsal view, dorsal part of the brain with anterior, dorsal, inner and posterior clusters marked by dotted circles. The gap in the dorsal cluster that reaches to the lateral side of the specimen is due to the cuticular plates that inhibit the signal at this position; b) frontoventral view, dorsal part of the brain indicated by the white dotted line, dorsoventral and ventral clusters are encircled by black dotted lines. Also the first ventral ganglion is visible; c) ventral view, ventral cluster and the four ventral ganglia are recognisable. $\mathrm{a}=$ an-

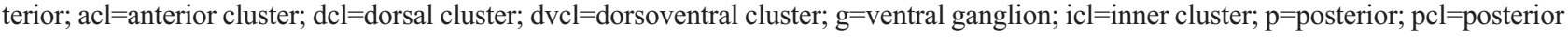
cluster; vcl=ventral cluster. Scale bars $=10 \mu \mathrm{m}$. 
very distinct transversal neurites (neurite bundles) that can be distinguished dorsal of the pharynx. They are here called dorsal commissures 1 to $6\left(\mathrm{dcm}_{1}-\mathrm{dcm}_{6}\right)$ (Fig. 2). They are numbered from dorsal to ventral. Dorsal commissures 2 and 3 appear at one level and are numbered from anterior to posterior. Dorsal commissures 1 to 3 connect the posterior clusters (Fig. 2a and 2b) and dorsal commissure 5 connects the anterior clusters (Fig. $2 \mathrm{c}$ and $2 \mathrm{~d}$ ). Ventral of the pharynx three distinct commissures can be identified. They are called ventral commissures 1 to $3\left(\mathrm{vcm}_{1}-\mathrm{vcm}_{3}\right)$ and are numbered from ventral to dorsal (Fig. 4). Ventral commissure 1 lies in the ventral cluster and runs into the dorsoventral cluster, unfortunately the signal is never intense enough to follow it until its termination.

\section{Dorsal longitudinal neurites}

On the dorsal side of the brain there are also some very distinctive longitudinal neurites. One is located at the midline of the body and therefore is not arranged bilaterally $\left(\mathrm{dn}_{\mathrm{m}}\right)$ (Fig. 5). It ends at about two third of the length of the cephalic plate. There are also four very prominent bilaterally arranged neurite bundles. They run to the anterior and end where the internal cirri, the cephalic papillae and the external cirri are positioned. The proximal and the distal bundle seem to terminate at the internal $\left(\mathrm{dn}_{\mathrm{ic}}\right)$ and the external cirri $\left(\mathrm{dn}_{\mathrm{ec}}\right)$, respectively (Fig. 5). The termination of the two middle ones $\left(\mathrm{dn}_{\mathrm{cp} \text { ? }}\right)$ cannot be followed because they merge into the anterior clusters of neurites (Fig. 5). These clusters are positioned where the cephalic papillae
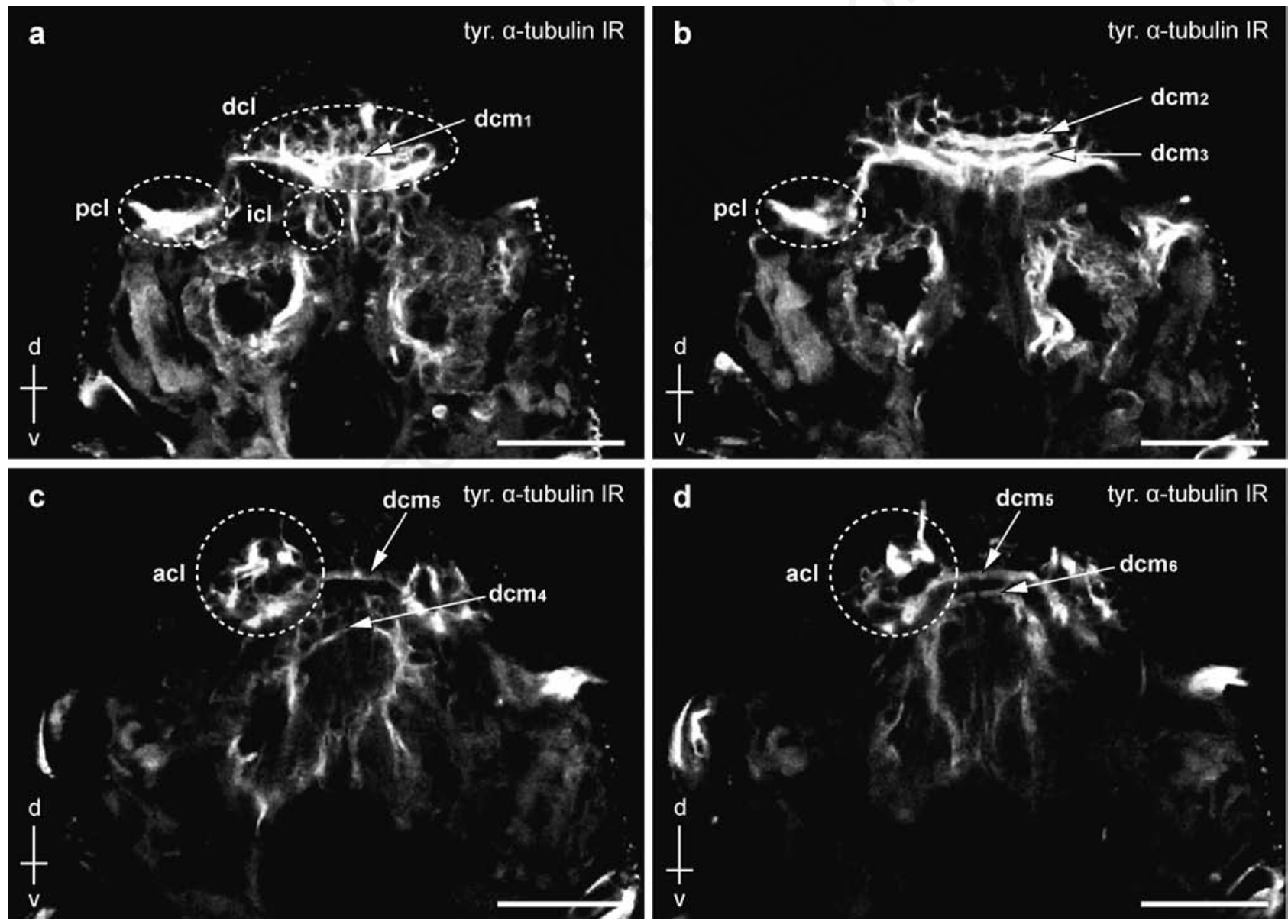

Fig. 2. Echiniscus testudo, tyrosinated $\alpha$-tubulin immunoreactivity, same specimen, single sections from one scan running from dorsal to ventral, anterior is up. The position of the single sections in the scan is marked by a white line on a dorsoventral axis. a) Dorsal, inner and posterior clusters are indicated by white circles. The first dorsal commissure is marked by an arrow; b) more ventrally dorsal commissures 2 and 3 are visible (marked by arrows). The posterior cluster (white circle) is still visible; c) anterior clusters (white circle) with the connecting fifth dorsal commissure and dorsal commissure 4, which is situated posterior of the fifth commissure, are visible (dorsal commissures 4 and 5 are indicated by arrows); d) more ventrally dorsal commissure 6 is appearing. It is situated posterior of dorsal commissure 5 (dorsal commissures 5 and 6 are indicated by arrows). The anterior cluster (white circle) is still visible. acl=anterior cluster; $\mathrm{d}=$ dorsal; $\mathrm{dcl}=\mathrm{dorsal}$ cluster; $\mathrm{dcm}=$ dorsal commissure; icl=inner cluster; $\mathrm{pcl}=$ posterior cluster; $\mathrm{v}=$ ventral. $\mathrm{Scale}$ bars $=20 \mu \mathrm{m}$. 
are situated. All these neurites originate from the dorsal cluster and can be assigned to the anterior clusters. The posterior clusters are connected with the dorsal cluster by another bilaterally arranged neurite bundle $\left(\mathrm{dn}_{\mathrm{pcl}}\right)$ (Fig. 5) and are positioned at the margins of the cephalic and the scapular plate where the cirri A and the clavae are located. It cannot be decided whether the cells of the posterior clusters innervate both, the cirri A and the clavae, or just one of these cephalic structures.

\section{The ventral ganglia}

The four ganglia (gI-gIV) are positioned ventrally (Figs. 1c and 6). Each ganglion is associated with one pair of legs. The ganglia are situated anterior to the associated legs (Figs. 1c and 6). The hemiganglia are connected via neurites, the ganglia commissures (Fig. 6). There are three further commissures that are not associated with the ventral ganglia. They are recognisable anterior to ventral ganglia II to IV each. They are here called commissures 1 to $3\left(\mathrm{~cm}_{1}-\mathrm{cm}_{3}\right)$. Hemiganglia in one row are also connected via neurite bundles, the ventral ganglia connectives (cn) (Fig. 6). Some specimens exhibit loops that show RFamide (Fig. 6d) and tyrosinated $\alpha$-tubulin (data not shown) IR. These loops are bilaterally arranged and originate from the connectives. They are only detectable between ventral ganglia II and III and between III and IV. They are located anterior to commissures 2 and 3. Each hemiganglion exhibits at least three neurites $\left(n_{1}-n_{3}\right)$ that reach to the lateral (Fig. 6). In every hemiganglion one of these neurites is connected to a soma that can be recognised by RFamide IR in the corresponding leg. These somata are numbered according to their corresponding leg ganglia $\left(\operatorname{lgg}_{1}-\operatorname{lgg}_{4}\right)$ (Fig. 6b and 6d). The hemiganglia of the first and the fourth ganglion appear to be positioned nearer to each other than the hemiganglia of the second and the third ganglion. This can vividly be seen when looking at the arrangement of the nuclei (Fig. 1c) and the length of the commissures (Fig. 6). The first ganglion is
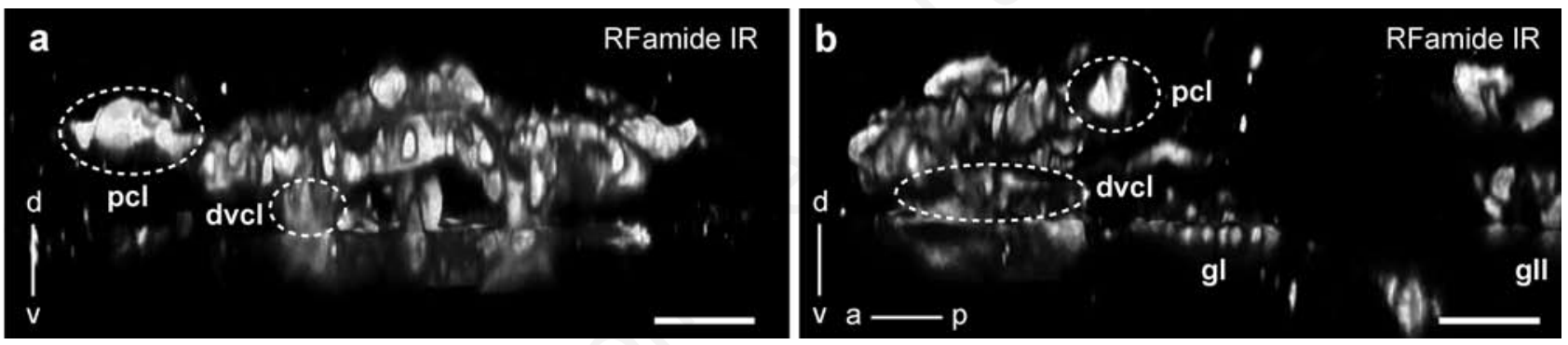

Fig. 3. Echiniscus testudo, RFamide immunoreactivity, Amira volume render, dorsal-ventral and anterior-posterior directions are indicated with the help of axes. a) Frontal view, posterior and dorsoventral clusters are indicated by white circles; b) lateral view, posterior and dorsoventral clusters (white circles) and the first two ventral ganglia are visible. $\mathrm{a}=$ anterior; $\mathrm{d}=\mathrm{dorsal}$; dvcl=dorsoventral cluster; $\mathrm{g}=$ ventral ganglion; $\mathrm{p}=$ posterior; $\mathrm{pcl}=$ posterior cluster; $\mathrm{v}=$ ventral. Scale bars $=10 \mu \mathrm{m}$.
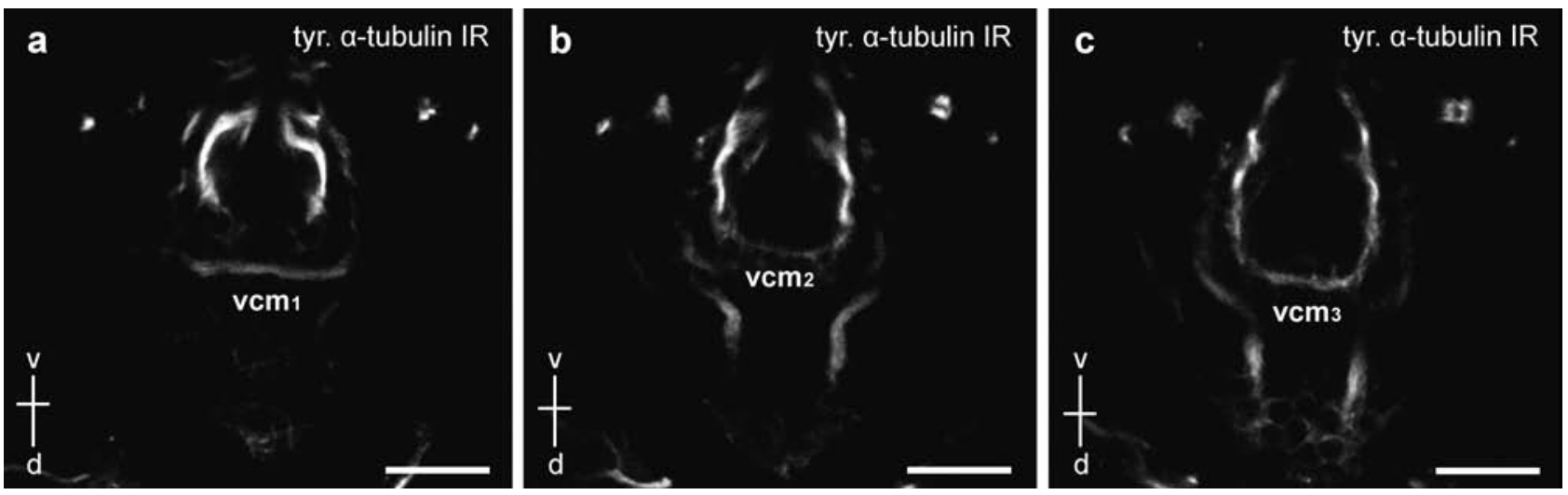

Fig. 4. Echiniscus testudo, tyrosinated $\alpha$-tubulin immunoreactivity, same specimen, single sections from one scan running from ventral to dorsal, anterior is up. The position of the single sections in the scan is marked by a white line on a dorsoventral axis. a) First ventral commissure; b) second ventral commissure; c) third ventral commissure. $d=d$ dorsal; v=ventral; vcm=ventral commissure. Scale bars=10 $\mu \mathrm{m}$. 
positioned very close to the ventral cluster of the brain (Figs. 1b, 1c and 6b). It is connected to the brain via two pairs of connectives (Fig. 6a). The inner of the two connectives $\left(\mathrm{cn}_{\mathrm{i}}\right)$ runs into the dorsoventral cluster. The outer connective $\left(\mathrm{cn}_{\mathrm{o}}\right)$ runs outside the dorsoventral cluster but its termination cannot be located. The first ventral commissure $\left(\mathrm{vcm}_{1}\right)$ runs into the dorsoventral cluster. From each fourth ventral hemiganglion one soma showing RFamide IR extends to the posterior. Each of these two posterior somata is positioned in line with its corresponding hemiganglion (Fig. 6d).

\section{DISCUSSION}

Authors working on the tardigrade brain correspond in describing its composition as lobate. The main differences arise from the interpretation of such a lobate brain in comparison with the tripartite arthropod brain. Are the lobes in the tardigrade brain homologous to segmental equivalents of the arthropod brain?

The first summary of the nervous system of Tardigrada is from Marcus (1929). He described central parts of the nervous system of Tardigrada to be composed of the brain (supraoesophageal ganglion; terminology after Marcus, 1929), a circumoesophageal ring, a suboeosphageal ganglion and four paired ventral ganglia. He also described the lobate appearance of the brain. Both Eutardigrada and Heterotardigrada have two pairs of lobes, two outer and two inner lobes. For the Heterotardigrada, even within Echiniscoidea, he reported different lobate appearances of the lobes, whereas Eutardigrada are united by the possession of a pair of long outer lobes and a median lobe flanked by a pair of inner lobes. Despite their variability, the uniting character of Heterotardigrada is a pair of short and wide outer lobes (Marcus, 1929).

Kristensen (1982) described the brain of the marine eutardigrade Halobiotus crispae Kristensen, 1982 to consist of three parts that might be homologous to the protocerebrum, deutocerebrum and tritocerebrum of arthropods. In the description of the brains of several arthrotardigrades the terms protocerebrum, deutocerebrum and tritocerebrum are used for the trilobed brains (Kristensen and Higgins, 1984a, 1984b).

Wiederhöft and Greven (1996) again stay with the neutral term lobes to describe the structure of the brain of the eutardigrade Milnesium tardigradum Doyère, 1840. They distinguished paired lateral outer lobes holding the eyes and a pair of inner lobes.

Independent of former descriptions and interpretations, in E. testudo we could identify dorsal, ventral and dorsoventral clusters that are comprised of layers of somata and neurites that could be detected by antibodies against tyrosinated $\alpha$-tubulin and against FMRFamide. In comparison with the lobate interpretation of the brain the anterior and posterior cluster of E. testudo together would comprise the outer lobe, the inner cluster would comprise the inner lobe and the dorsoventral cluster would represent the third lobe. The dorsoventral clusters look very massive (Figs. $1 \mathrm{~b}$ and $3 \mathrm{~b}$ ) and seem to be connected to the dorsal part of the brain and the ventral cluster on a broad base. This could either be interpreted as ring-like and would match the description of Marcus (1929) and Zantke et al. (2008). In contrast, it could be interpreted as a third lobe and therefore would match the description for example of Kristensen (1982), Kristensen and Higgins (1984a, 1984b) and Persson et al. (2012). In their view, the lobes in the tardigrade brain can be interpreted to reflect an organisation into proto-, deuto- and tritocerebrum. We think, however, that our results are not supportive in this respect. The dorsal cluster is a large compartment without any indication of segmentation. Metameric patterns are, when present at all, reflected by the lobes, but these can also be explained functionally as extensions of the dorsal cluster towards the sensory structures. The dorsal neurites running to the internal and external cirri and to the cephalic papillae are gathered in the anterior clusters and the neurites innervating cirri A and the clavae are gathered in the posterior clusters. As we interpret our anterior and posterior cluster to be united in the outer lobe there would be just one lobe supplying all cephalic structures. Even if we assume the anterior and the posterior cluster not to be united in the outer lobe, then still the external cirri, the cephalic papillae and the internal cirri would be innervated by one lobe and not by two (Kris-

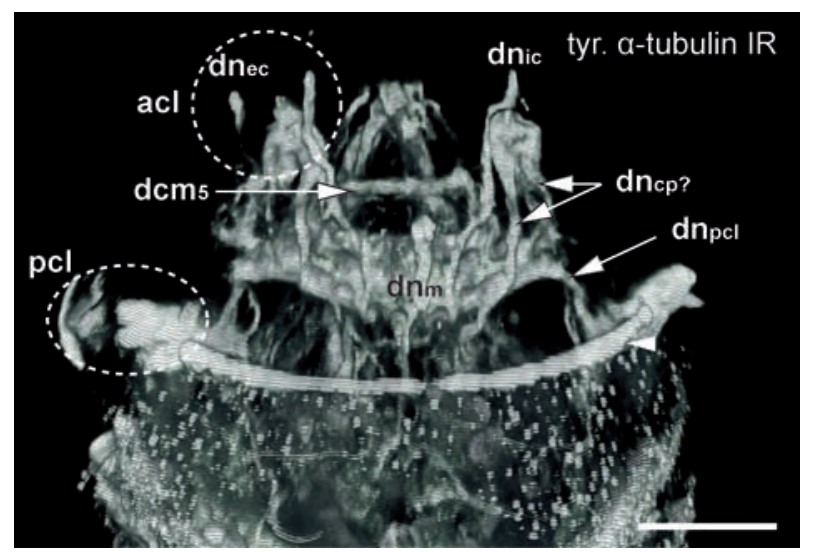

Fig. 5. Echiniscus testudo, tyrosinated $\alpha$-tubulin immunoreactivity Amira volume render, dorsal view, anterior is up. Anterior and posterior clusters are encircled. Dorsal commissure 5, as well as several dorsal neurites are distinguishable. The distinctive structure indicated by an arrowhead is part of the cuticle. acl=anterior cluster; $\mathrm{dcm}=$ dorsal commissure; $\mathrm{dn}=$ dorsal neurite $\left(_{\mathrm{cp}}=\right.$ cephalic papilla; $=$ external cirrus; ic $_{\text {ic }}=$ internal cirrus; ${ }_{\mathrm{m}}=$ median; ${ }_{\mathrm{pcl}}=$ posterior cluster); $\mathrm{pcl}=$ posterior cluster. Scale bar $=20 \mu \mathrm{m}$. 

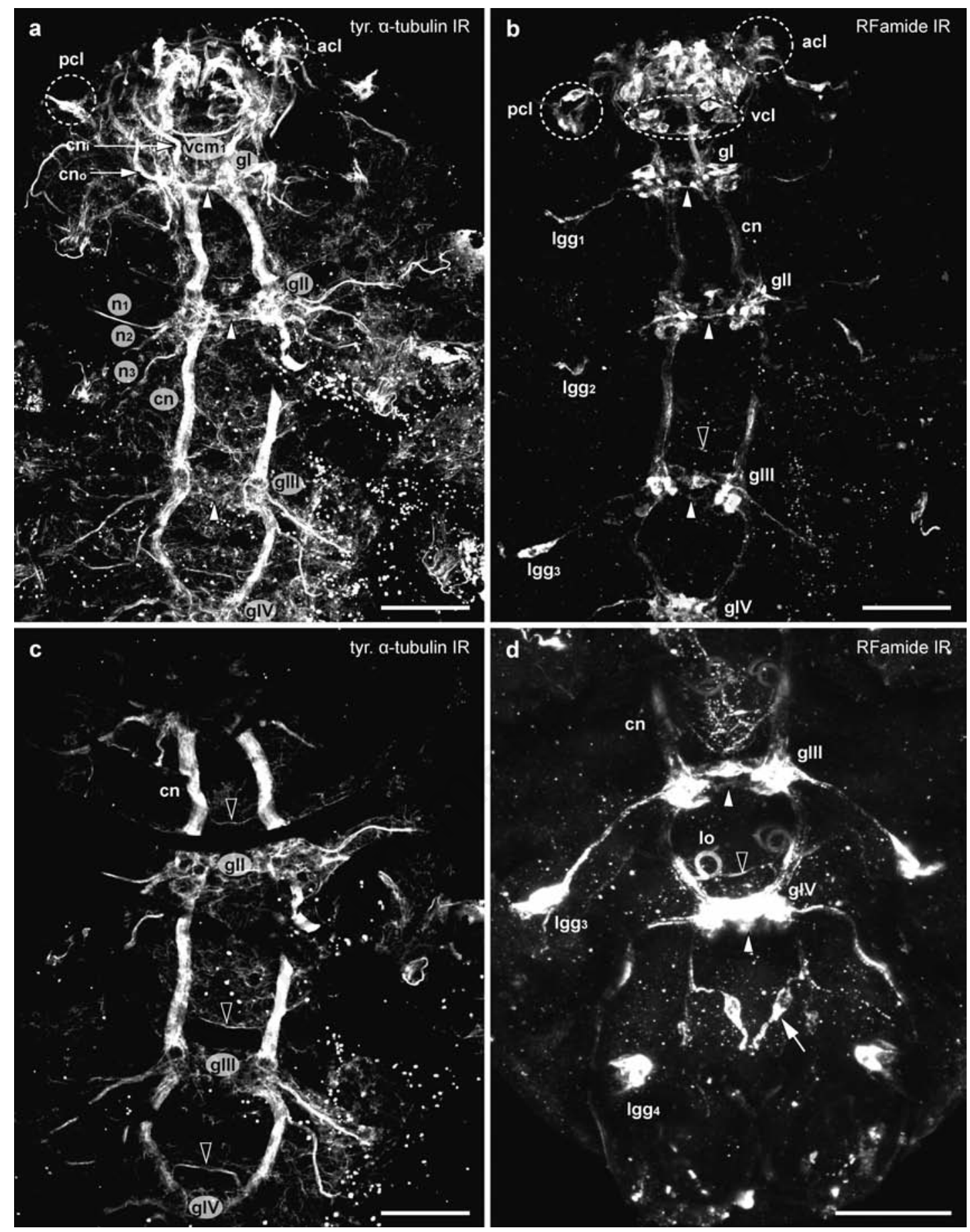

Fig. 6. Echiniscus testudo, ventral view, anterior is up. Unspecific dots are due to cuticular structures. a-c) Same specimen. a, c) Tyrosinated $\alpha$-tubulin immunoreactivity. b, d) RFamide immunoreactivity, maximum projection.a) Maximum projection. The anterior and posterior clusters (indicated by white circles), the ventral commissure 1, the four ventral ganglia with their commissures (arrowheads) and connectives, the three neurites originating from each hemiganglion and the inner and outer connectives (arrows) originating from the first ventral ganglion are distinguishable; b) anterior, posterior and ventral clusters (marked by white circles), the ventral ganglia with their commissures (arrowheads) and connectives, one ganglion independent commissure (open arrowhead) and somata of the leg ganglia are visible; c) single section. Ventral ganglia 2-4, connectives and the ganglia independent commissures (open arrowheads) are visible; d) detail of the posterior part of a specimen with the third and fourth ventral ganglion, their commissures (arrowheads), the connectives, one ganglion independent commissure anterior of the fourth ventral ganglion (open arrowhead), loops, somata of the leg ganglia and the two posterior somata (arrow). acl=anterior cluster; $\mathrm{cn}=$ connective $\left(\mathrm{i}=\mathrm{inner} ;{ }_{\mathrm{o}}=\mathrm{outer}\right)$; g=ventral ganglia; lgg=soma of the leg ganglion; lo=loop; $\mathrm{n}=$ neurite; $\mathrm{pcl}=$ posterior cluster; $\mathrm{vcl}=$ ventral cluster; $\mathrm{vcm}=$ ventral commissure. Scale $\mathrm{bars}=25 \mu \mathrm{m}$. 
tensen, 1987). Also Dewel and Dewel (1996) interpreted the brain of Echiniscus viridissimus Peterfi, 1956 not to consist of a proto-, deuto- and a tritocerebrum (Dewel et al., 1999). However, they described the brain to be composed of metameric compartments that all together correspond to the protocerebrum of arthropods.

Persson et al. (2012) describe the first ventral ganglion to be connected with the subpharyngeal ganglion via the ventral longitudinal nerve cord and with the brain via an outer and an inner connective with the outer and the ventrolateral lobes, respectively. The ventral lobes are also connected to the subpharyngeal ganglion. Like Zantke et al. (2008), we could not detect such a connection between the ventral cluster and the first ventral ganglion with our set of antibodies. But a connection between the first ventral ganglion and the brain was detectable. The inner connective runs through the dorsoventral cluster to the dorsal part of the brain and the outer connective runs outside the dorsoventral cluster to the dorsal part of the brain. The commissure of the ventral cluster $\left(\mathrm{vcm}_{1}\right)$ runs into the dorsoventral clusters. A ventrally situated commissure that connects the dorsoventral clusters could not surely be detected. It can be stated that our findings are similar to the description of the situation in H. crispae (Persson et al., 2012). That we could not detect a connection between the ventral cluster and the first ventral ganglion does not mean that $E$. testudo has no such connection but instead might be due to the lack of the right antibody. If the connectives are really missing, it would be a support that the ventral cluster does not depict the subpharyngeal ganglion. Furthermore, if we assume that the posterior cluster is part of the outer lobe and as such is interpreted as the protocerebrum because of the innervation of the cirrus $\mathrm{A}$ and the clava (Kristensen, 1987), then the protocerebrum would be connected to the first ventral ganglion, instead of the tritocerebrum. This also contradicts an interpretation of a tripartite brain where the three lobes are homologous to the proto-, deuto- and tritiocerebrum of Arthropoda. Likewise no support for a tripartite organisation of the brain or the existence of a subpharyngeal ganglion comes from developmental studies (Hejnol and Schnabel, 2005, 2006).

Contrary to Zantke et al. (2008), our study as well as Persson et al. (2012) and former authors (Marcus, 1929; Greven and Kuhlmann, 1972) could show clearly visible commissures in the ventral ganglia. Additionally, we could also detect three commissures that are independent of the ventral ganglia. They are situated anterior of the second, the third and the fourth ventral ganglion. E. testudo therefore resembles a true rope-ladder like nervous system. In a recent review Whitington and Mayer (2011) stated that the nerve cord of Onychophora has little in common with the rope-ladder arrangement of Arthropoda, it is more similar to an orthogonal arrangement.
Between the second and the third ganglion, bilaterally arranged neurites could be detected that run in a loop to the dorsal part of the specimens. These loops could not be detected in every examined individual. Whether this might be linked to age or maybe to molting cannot be decided because none of these parameters were recorded for this study.

\section{CONCLUSIONS}

The brain of E. testudo comprises different clusters. One anterior and one posterior cluster can be united in an outer lobe. Furthermore, a pair of inner clusters can be distinguished which can be interpreted as part of the inner lobes. The last pair of clusters (dorsoventral clusters) that could be distinguished connects the dorsal part of the brain and the ventral cluster. All cephalic structures are innervated by the clusters of the outer lobes. In our view the results on the nervous system of E. testudo are not convincing for a statement that the lobate organisation is homologous to the metameric organisation of the brain into proto-, deuto- and tritocerebrum of Arthropoda. The interpretation of existing data on the organisation of the brain of Tardigrada is highly heterogeneous. Some morphological and developmental data are contradictory and we think it is too early to conclude that Tardigrada possess a tripartite brain resembling the arthropod-like proto-, deuto- and tritocerebrum. On the other hand the organisation of the ventral ganglia is clear. In contrast to Onychophora $E$. testudo shows a rope-ladder like appearance of the ventral ganglia like Arthropoda.

\section{ACKNOWLEDGMENTS}

We thank Dr. Birgen H. Rothe and Stephan Henne for constructive discussion and criticism as well as Prof. Steffen Harzsch for constructive discussion during a morphology workshop sponsored by the German Zoological Foundation. We also thank two reviewers for constructive criticism that helped to improve this manuscript.

\section{REFERENCES}

Basse A, 1905. [Beiträge zur Kenntnis des Baues der Tardigraden]. [Article in German]. Z. Wiss. Zool. 80:259-280.

Campbell LI, Rota-Stabelli O, Edgecombe GD, Marchioro T, Longhorn SJ, Telford MJ, Philippe H, Rebecchi L, Peterson KJ, Pisani D, 2011. MicroRNAs and phylogenomics resolve the relationships of Tardigrada and suggest that velvet worms are the sister group of Arthropoda. PNAS 108:15920-15924.

Crowe JH, Newell IM, Thomson WW, 1970. Echiniscus viridis (Tardigrada): fine structure of the cuticle. Trans. Am. Microsc. Soc. 89:316-325.

Degma P, Bertolani R, Guidetti R, 2009-2012. Actual checklist of Tardigrada species. Ver. 20: 17-01-2012. Available from: http://www.tardigrada.modena.unimo.it/miscellanea/Actual $\% 20$ checklist $\% 20$ of $\% 20$ Tardigrada.pdf 
Degma P, Guidetti R, 2007. Notes to the current checklist of Tardigrada. Zootaxa 1579:41-53.

Dewel RA, Budd GE, Castano DF, Dewel WC, 1999. The organization of the subeosphageal nervous system in tardigrades: insights into the evolution of the arthropod hypostome and tritocerebrum. Zool. Anz. 238:191-203.

Dewel RA, Clark Jr WH, 1973a. Studies on the tardigrades. I. Fine structure of the anterior foregut of Milnesium tardigradum Doyère. Tissue \& Cell 5:133-146.

Dewel RA, Clark Jr WH, 1973b. Studies on the tardigrades. II. Fine structure of the pharynx of Milnesium tardigradum Doyère. Tissue \& Cell 5:147-159.

Dewel RA, Clark Jr WH, 1973c. Studies on the tardigrades. III. Fine structure of the esophagus of Milnesium tardigradum Doyère. Tissue \& Cell 5:161-169.

Dewel RA, Dewel WC, 1996. The brain of Echiniscus viridissimus Peterfi, 1956 (Heterotardigrada): a key to understanding the phylogenetic position of tardigrades and the evolution of the arthropod head. Zool. J. Linn. Soc. 116:3549.

Doyère M, 1840. [Mémoire sur les Tardigrades]. [Article in French]. Ann. Sci. Nat. 2, 14:269-361

Dunn CW, Hejnol A, Matus DQ, Pang K, Browne WE, Smith SA, Seaver E, Rouse GW, Obst M, Edgecombe GD, Sørensen MV, Haddock SHD, Schmidt-Rhaesa A, Okus A, Kristensen RM, Wheeler WC, Martindale MQ, Giribet G, 2008. Broad phylogenomic sampling improves resolution of the animal tree of life. Nature 452:745-749.

Giribet G, 2003. Molecules, development and fossils in the study of metazoan evolution; Articulata versus Ecdysozoa revisited. Zoology 106:303-326.

Giribet G, Edgecombe GD, 2012. Reevaluating the arthropod tree of life. Annu. Rev. Entomol. 57:167-186.

Greeff R, 1865. [Ueber das Nervensystem der Bärthierchen, Arctiscoida C.A.S. Schultze (Tardigraden Doyère) mit besonderer Berücksichtigung der Muskelnerven und deren Endigungen]. [Article in German]. Arch. Mikrosk. Anat. $1: 101-122$.

Greven H, Kuhlmann D, 1972. [Die Struktur des Nervengewebes von Macrobiotus hufelandi C.A.S. Schultze (Tardigrada)]. [Article in German]. Z. Zellforsch.132:131-146.

Guidetti R, Bertolani R, 2005. Tardigrade taxonomy: an updated check list of the taxa and a list of characters for their identification. Zootaxa 845:1-46.

Guidetti R, Schill RO, Bertolani R, Dandekar T, Wolf M, 2009. New molecular data for tardigrade phylogeny, with the erection of Paramacrobiotus gen. nov. J. Zool. Syst. Evol. Res. 47:315-321.

Guil N, Giribet G, 2012. A comprehensive molecular phylogeny of tardigrades: adding genes and taxa to a poorly resolved phylum level phylogeny. Cladistics 28:21-49.

Hejnol A, Schnabel R, 2005. The eutardigrade Thulinia stephaniae has an indeterminate development and the potential to regulate early blastomere ablations. Development 132:1349-1361.

Hejnol A, Schnabel R, 2006. What a couple of dimensions can do for you: Comparative developmental studies using 4D microscopy: examples from tardigrade development. Integr. Comp. Biol. 46:151-161.

Jørgensen A, Faurby S, Hansen JG, Møbjerg N, Kristensen RM,
2010. Molecular phylogeny of Arthrotardigrada (Tardigrada). Mol. Phylogenet. Evol. 54:1006-1015.

Jørgensen A, Kristensen RM, 2004. Molecular phylogeny of Tardigrada: investigation of the monophyly of Heterotardigrada. Mol. Phylogenet. Evol. 32:666-670.

Jørgensen A, Møbjerg N, Kristensen RM, 2011. Phylogeny and evolution of the Echiniscidae (Echiniscoidea, Tardigrada): an investigation of the congruence between molecules and morphology. J. Zool. Syst. Evol. Res. Suppl. 49:6-16.

Kinchin IM, 1994. The biology of tardigrades. Portland Press, London: 186 pp.

Kristensen RM, 1981. Sense organs of two marine arthrotardigrades (Heterotardigrada, Tardigrada). Acta Zool. 62:27-41.

Kristensen RM, 1982. The first record of cyclomorphosis in Tardigrada based on a new genus and species from Arctic meiobenthos. Z. Zool. Syst. Evolutionsforsch. 20:249-270.

Kristensen RM, 1987. Generic revision of the Echiniscidae (Heterotardigrada), with a discussion of the origin of the family, p. 261-335. In: R. Bertolani (ed.), Biology of Tardigrades. Selected Symposia and Monographs, U.Z.I. 1. Mucchi Publ.

Kristensen RM, Higgins RP, 1984a. A new family of Arthrotardigrada (Tardigrada: Heterotardigrada) from the Atlantic Coast of Florida, U.S.A. Trans. Am. Microsc. Soc. 103:295311.

Kristensen RM, Higgins RP, 1984b. Revision of Styraconyx (Tardigrada: Halechiniscidae), with descriptions of two new species from Disko Bay, West Greenland. Smithson. Contrib. Zool. 391:1-40.

Marcus E, 1929. [Tardigrada], p. 1-608. In: H.G. Bronn (ed.), [Klassen und Ordnungen des Tier Reichs, 5]. [Book in German]. Akademische Verlagsgesellschaft ed.

Nelson DR, 1991. Tardigrada, p. 501-521. In: J.H. Thorp and A.P. Covich (eds.), Ecology and classification of North American freshwater invertebrates. Academic Press.

Nichols PB, Nelson DR, Garey JR, 2006. A family level analysis of tardigrade phylogeny. Hydrobiologia 558:53-60.

Persson D, Halberg KA, Jørgensen A, Møbjerg N, Kristensen RM, 2012. Neuroanatomy of Halobiotus crispae (Eutardigrada: Hypsibiidae): Tardigrade brain structure supports the clade Panarthropoda. J. Morph. 273:1227-1245.

Plate L, 1889. [Beiträge zur Naturgeschichte der Tardigraden]. [Article in German]. Zool. Jb. Abt. Anat. Ontog. 3:487-550.

Rahm G, 1937a. [Eine neue Tardigraden-Ordnung aus den heißen Quellen von Unzen, Insel Kyushu, Japan]. [Article in German]. Zool. Anz. 120:65-71.

Rahm G, 1937b. A new ordo of tardigrades from the hot springs of Japan (Furu-Yu section, Unzen). Annot. Zool. Jpn. 16:345-352.

Ramazzotti G, Maucci W, 1983. The phylum Tardigrada, $3^{\text {rd }}$ ed. English translation by Beasley CW, 1995. Mem. Ist. Ital. Idrobiol 41:1-1012.

Richter S, Loesel R, Purschke G, Schmidt-Rhaesa A, Stach T, Wanninger A, Brenneis G, Faller S, Fritsch M, Hausen H, Heuer C, Kaul S, Møller OS, Müller CHG, Rieger V, Rothe B, Stegner MEJ, Harzsch S, 2010. Invertebrate neurophylogeny: suggested terms and definitions for a neuroanatomical glossary. Front. Zool. 7:29.

Rota-Stabelli O, Campbell L, Brinkmann H, Edgecombe GD, Longhorn SJ, Peterson KJ, Pisani D, Philippe H, Telford MJ, 
2011. A congruent solution to arthropod phylogeny: phylogenomics, microRNAs and morphology support monophyletic Mandibulata. Proc. R. Soc. B 278:298-306.

Sands CJ, Convey P, Linse K, McInnes SJ, 2008. Assessing meiofaunal variation among individuals utilizing morphological and molecular approaches: an example using the Tardigrada. BMC Ecology 8:7.

Schmidt-Rhaesa A, Bartolomaeus T, Lemburg C, Ehlers U, Garey JR, 1998. The position of the Arthropoda in the phylogenetic system. J. Morphol. 238:263-285.

Schuster RO, Nelson DR, Grigarick AA, Christenberry D, 1980. Systematic criteria of the Eutardigrada. Trans. Am. Microsc. Soc. 99:284-303.

Walz B, 1978. Electron microscopic investigation of cephalic sense organs of the tardigrade Macrobiotus hufelandi C.A.S. Schultze. Zoomorphologie 89:1-19.

Walz B, 1979. Cephalic sense organs of Tardigrada. Current re- sults and problems. Zesz. Nauk. Uniw. Jagiellonsk. Pr. Zool. 25:161-168.

Whitington PM, Mayer G, 2011. The origins of the arthropod nervous system: Insights from the Onychophora. Arth. Struct. Dev. 40:193-209.

Wiederhöft H, Greven H, 1996. The cerebral ganglia of Milnesium tardigradum Doyère (Apochela, Tardigrada): three dimensional reconstruction and notes on their ultrastructure. Zool. J. Linn. Soc. 116:71-84.

Wiederhöft H, Greven H, 1999. Notes on head sensory organs of Milnesium tardigradum Doyère, 1840 (Apochela, Eutardigrada). Zool. Anz. 238:338-346.

Zantke J, Wolff C, Scholtz G, 2008. Three-dimensional reconstruction of the central nervous system of Macrobiotus hufelandi (Eutardigrada, Parachela): implications for the phylogenetic position of Tardigrada. Zoomorphology 127:21-36. 